\title{
Improvement of Bachelors' Professional Mathematical Competence in the Field of Modeling for Oil and Gas industry
}

\author{
https://doi.org/10.3991/ijoe.v16i10.15321 \\ Anatoly Kozlov ${ }^{(凶)}$, Olga Tamer, Svetlana Lapteva \\ Branch of Tyumen Industrial University, Noyabrsk, Russia \\ nashdoceyandex.ru
}

\begin{abstract}
The study is devoted to improving the professional training of students in the field of mathematical modeling in the oil and gas industry. Deeper integration into the training of modern statistical methods and models is used to improve the educational efficiency and develop mathematical models of technological processes of the oil and gas industry. To test the proposed models, a pedagogical experiment with 189 students aged 19 to 21 is performed. The research is based on the November Institute of Oil and Gas in the Yamalo-Nenets Autonomous District. The outcomes of training under the new program are evaluated at three levels of competency formation in accordance with the university's assessment systems. This approach ensures a level playing field for all respondents. The relevance of improving the competence of students in the field of mathematics is proved through the increase in grades at all three levels of competency formation.

The study describes in detail the system of profile differentiation of the mathematical training, which is based on a modular competency approach and compares various approaches and methods of professional competence formation among oil and gas workers.
\end{abstract}

Keywords-Oil and gas business, mathematical competence, mathematical modeling, professional education.

\section{Introduction}

Mathematical education is among the basic elements of the university training of future engineers. Therefore, in the process of professional education, an important role belongs to the formation of the mathematical competence of an engineer, being a crucial component of his professional skills $[1,2]$. The main goals of creating mathematical competence are (1) studying the basic concepts and objects of mathematical modeling within the challenges of the oil and gas industry, (2) developing clear logical thinking, and (3) analyzing technological processes in the oil and gas industry [35].

Mathematical methods are used to study oil reservoir mechanics, oil production processes, pumping and processing of hydrocarbons, to examine geological and tech- 
nical circumstances in the process of drilling, to forecast parameters when assessing reserves of hydrocarbon deposits in the face of uncertainty, etc. [6-8]. The fuzziness of the initial data and the objective fuzziness of the models in oil and gas geology leads to the introduction of the concept of fuzzy modeling when creating mathematical models of oil and gas perspective objects and evaluating their parameters. Fuzzy modeling consists of converting fuzzy data and a system of fuzzy petrophysical models into models of the geological structure [9].

When improving the professional training of specialists in the field of modeling in the oil and gas industry, it is also relevant for students to master modern statistical methods to increase the efficiency of organizing laboratory and field experiments and ensure the reliability of the information base. During the mathematical modeling, each object has a set of characteristics, which can serve as indicators of the properties of working agents (drilling mud, grouting mixture, etc.), operating characteristics of the equipment (mud pump rate, rotor torque, pressure in the elements of the circulation system, etc.), information on external influences (reservoir pressure and temperature, rock and fluid properties, bedding angles, etc.), and the nomenclature of materials and equipment used. As an image or a class of a situation, one can use a variety of representations (stable or unstable section, successful or unsuccessful work results, condition of the well, slides, cavings, sticking of strings).

The developed innovative didactic system for the formation of professional mathematical competence of bachelors allows transforming scientific knowledge into the academic. Besides, it adjusts professional training of bachelors to modern requirements in the field of mathematical modeling in the oil and gas industry. For this reason, current research contributes to the theory and methodology of professional education.

\section{$2 \quad$ Literature Overview}

In this study, the experience of mainly Russian scientists is considered. In particular, the research is based on the fundamental principles of professional training, differentiation of university disciplines and teaching methods [10,11]. Due to the rapid change in the technical base and oil and gas extraction and refining technologies, the development of educational technologies for specialists' training is of particular interest $[10,12]$. The use of highly specialized skills is also associated with preparing students for future work in an informational digital environment. It includes pedagogical techniques and training programs that should take into account the digital environment and use it at all stages of training [13,14]. The achievements of modularity, the succession of educational material, mathematical research methods, and solutions of practical life problems described by Russian scholars are used to create the unique training program within the current paper [15-17].

The oil and gas industry in Russia needs a constant influx of professionally trained specialists, able to work immediately after graduation from a higher educational institution. Therefore, the solution of practice-oriented training problems is of great importance. Approaches to solving such challenges are considered by several Russian 
researchers $[5,18]$. The modern practice of training a future specialist requires an active inclusion of a student in all types of activities [4,19]. These are, first of all, the tasks of mathematical modeling of physical processes and the application of probabilistic and statistical analysis methods for decision making in the oil and gas industry $[1,7]$.

During the preparation of narrow-profile specialists, the matter of professional orientation of training comes to the fore. These issues are reviewed by many Russian scientists, in particular, in works devoted to the mathematical education of students of higher educational institutions [20-22]. In the oil and gas industry, methods of modular training and the integration of mathematical statistics in resolving practical difficulties on the technical and managerial levels are used for a long time [6, 23]. In international practice, STEM-training [8] is also increasingly applied to solve these problems. On the one hand, this enables the integration of students' mathematical skills and the natural science knowledge with highly specialized skills of the chosen speciality. On the other hand, the use of STEM methods makes the integration of the educational process into a digital environment easier and involves more modern teaching methods.

Foreign higher education system accumulated rich experience in improving the professional training of students in the field of innovative technologies that are used at certain stages of education modernization. They are associated with profile differentiation, the integration of science and technology, and based on practice- and professional-oriented approaches [24-27]. A large number of studies examine competency models that remain an effective means of determining the requirements for professional education and guiding the evaluation and development of professional and practical training programs $[2,19,28-30]$. Reiss and Obersteiner discuss the construction of competency models applied to the study of mathematics. The proposed models can be considered as useful tools for determining, understanding, and diagnosing mathematical competence [2]. Furthermore, numerous works review the relation between teachers' professional knowledge and quality of training in the field of mathematical education [30,31].

The development of modeling competencies has received much attention from scientists [28]. Many approaches to solving the problem of changing education in the field of mathematics in connection with the increasing demands on the quality and volume of knowledge are proposed. These issues are especially relevant for specialties that provide the foundation for the existence of modern civilization and the infrastructure of the world economy. Among other areas, the oil and gas complex [32-34] should be included in such specialties. However, these issues continue to be among the most challenging due to the rapid development of computer technologies of modeling. Thus, this subject requires further study.

\section{Methods}

To achieve the goal of the research and attain its objectives, a set of methods is applied. Among them are modeling and design of didactic theories; a pedagogical exper- 
iment, which enables obtaining data on the level of students' training; mathematical and statistical methods; and software for processing the results of the examination. The current study is based on the November Institute of Oil and Gas in the YamaloNenets Autonomous District. The results of the pedagogical experiment are evaluated under the fact that the level of students' two-year training under the new program corresponds or slightly exceeds the results demonstrated by the previous classes of the same educational course. The experiment involves 189 students (92 women and 97 men) aged 19 to 21 years, who agree to take part in the examination voluntarily. The research is conducted throughout the 2018 - 2019 academic year. The modular method is applied for the profile differentiation of students within the training program 21.03.01 "Oil and Gas Business". The respondents received a full description of the future teaching methodology and the required clarification. A randomly selected group of students of the same age and the same number of men and women is chosen as a control sample.

The assessment of the effectiveness of the mathematical competence formation is performed in the form of tests and exams. Students' success is evaluated by three types of mathematical competence: actual knowledge, theoretical knowledge, and the ability to solve practical problems. The assessment method is identical for the control and research groups and is carried out by the same composition of teachers on a 12point scale. Since the gender division is not significant within the current study, it is not taken into account. The research is aimed at testing the hypothesis that the use of the developed methodology for the formation of mathematical competence shows different results from the ones of a regular curriculum. To test this hypothesis, the grades for students from the experimental and control groups are compared.

The reliability and scientific validity of the results are driven by the development of adequate diagnostic methods, quantitative and qualitative analysis of experimental data, and the use of research results in pedagogical practice. During the development of a methodology for testing the experiment outcomes, the level of formation of students' professional mathematical competence is chosen as an integrative indicator of the effectiveness of the developed technological approaches. In determining the level of professional mathematical competence formation, generalized knowledge and skills in solving problems at three levels of content profiling (factual, theoretical, and practical) are evaluated.

Based on the results, processed by methods of mathematical statistics, the dynamics of differential indicators of students' professional mathematical competence development is studied. The mathematical competence is formed on the integrative approach. Thus, the non-parametric criterion $\chi 2$ (chi-square) is used along with the multivariate correlation and variance analysis. On their basis, the hypothesis about the effectiveness of the profile differentiation of mathematical training is confirmed.

This study is aimed at implementing the professional orientation of the mathematical training of university students within the program 21.03.01 "Oil and Gas Business".

Research objectives can be defined as follows: 
1. Implement the system of profile differentiation of the mathematical training among university students on the basis of a modular competency-based approach.

2. Perform the application of a modular competency-based approach to the organization of professional education for specialists of the 21.03.01 "Oil and Gas Business" training program.

3. Develop a systematic diagnosis of differentiated indicators that determine the level of formation of the professional mathematical competence of university students.

\section{$4 \quad$ Results}

Table 1 shows the distribution of the number of students who received one or another grade when testing three types of competency, their comparison by the Chisquare parameter, and the correlation coefficient between the experimental and control groups. All participants received grades from 7 to 12 .

Table 1. Grades of the experimental and control groups

\begin{tabular}{|c|c|c|c|c|c|c|}
\hline & \multicolumn{2}{|c|}{ Factual Level } & \multicolumn{2}{|c|}{ Theoretical Level } & \multicolumn{2}{|c|}{ Practical Level } \\
\hline & \multicolumn{6}{|c|}{ Number of students } \\
\hline Grade & $\begin{array}{c}\text { Experimental } \\
\text { group }\end{array}$ & $\begin{array}{l}\text { Control } \\
\text { group }\end{array}$ & $\begin{array}{l}\text { Experimental } \\
\text { group }\end{array}$ & $\begin{array}{l}\text { Control } \\
\text { group }\end{array}$ & $\begin{array}{c}\text { Experimental } \\
\text { group }\end{array}$ & $\begin{array}{l}\text { Control } \\
\text { group }\end{array}$ \\
\hline 12 & 44 & 18 & 41 & 15 & 39 & 9 \\
\hline 11 & 32 & 19 & 30 & 22 & 29 & 16 \\
\hline 10 & 33 & 24 & 33 & 24 & 35 & 28 \\
\hline 9 & 37 & 54 & 39 & 49 & 39 & 51 \\
\hline 8 & 20 & 44 & 22 & 47 & 26 & 48 \\
\hline 7 & 32 & 39 & 33 & 41 & 30 & 46 \\
\hline $\begin{array}{l}\text { Chi-square } \\
\text { parameter }\end{array}$ & & $5,12 \mathrm{E}-13$ & & $2,37 \mathrm{E}-13$ & & $1,62 \mathrm{E}-26$ \\
\hline Correlation & & $-0,37109$ & & $-0,34521$ & & $-0,24841$ \\
\hline
\end{tabular}

The analysis of the chi-square parameter shows the significance of the discrepancy between the frequencies of the estimates obtained in the control and experimental groups. It proves that the improvement in the indicators of mathematical competence among students of the experimental group is not random. As expected values, the results of the control group evaluation, which coincide with the average indicators for this discipline in other study groups, are used.

The grades correlation shows a weak level of compliance. For assessment by the parameter of practical knowledge, the absence of correlation should be admitted. It is explained by a random change in the level of distribution of grades among students. The number of students who received one or another grade is poorly correlated in both groups due to the personal characteristics of students, the degree of engagement, motivation, and other aspects.

The results of the dispersion analysis are presented in Tables 2, 3, and 4. The null hypothesis for analysis of variance is the assumption that the change in estimates of the experimental group is not significant and is random. 
Table 2. Dispersion analysis of the factual level of mathematical competence

\begin{tabular}{|c|c|c|c|c|c|c|}
\hline Groups & Rate & Sum & Average & Dispersion & & \\
\hline 1 & 6 & 189 & 33 & 61,6 & & \\
\hline 2 & 6 & 189 & 33 & 220 & & \\
\hline \multicolumn{7}{|c|}{ Dispersion analysis } \\
\hline Source of variation & SS & $d f$ & MS & $\boldsymbol{F}$ & P-value & F critical \\
\hline Between groups & 0 & 1 & 0 & 0 & 1 & 4,964602744 \\
\hline Within groups & 1408 & 10 & 140,8 & & & \\
\hline Total & 1408 & 11 & & & & \\
\hline
\end{tabular}

The value of the obtained variance of 4.96 is significantly higher than the expected critical level of 1 , which indicates that the assumption of the variance study is incorrect, and the change in the estimates obtained exists.

Table 3. Dispersion analysis of the theoretical level of mathematical competence

\begin{tabular}{|c|c|c|c|c|c|c|}
\hline Groups & Rate & Sum & Average & Dispersion & & \\
\hline 1 & 6 & 189 & 33 & 46 & & \\
\hline 2 & 6 & 189 & 33 & 208,4 & & \\
\hline \multicolumn{7}{|c|}{ Dispersion analysis } \\
\hline Source of variation & $S S$ & $d f$ & MS & $\boldsymbol{F}$ & P-value & F critical \\
\hline Between groups & 0 & 1 & 0 & 0 & 1 & 4,964602744 \\
\hline Within groups & 1272 & 10 & 127,2 & & & \\
\hline Total & 1272 & 11 & & & & \\
\hline
\end{tabular}

The value of the obtained dispersion of 4.96 for all studied levels is identical and significantly exceeds the boundary value.

Table 4. Dispersion analysis of the practical level of mathematical competence

\begin{tabular}{|c|c|c|c|c|c|c|}
\hline Groups & Rate & Sum & Average & Dispersion & & \\
\hline 1 & 6 & 189 & 33 & 30 & & \\
\hline 2 & 6 & 189 & 33 & 321,6 & & \\
\hline \hline \multicolumn{7}{|c|}{ Dispersion analysis } \\
\hline Source of variation & $\boldsymbol{S S}$ & $\boldsymbol{d} \boldsymbol{f}$ & $\boldsymbol{M S}$ & $\boldsymbol{F}$ & $\boldsymbol{P}$-value & F critical \\
\hline Between groups & 0 & 1 & 0 & 0 & 1 & 4,964602744 \\
\hline Within groups & 1758 & 10 & 175,8 & & & \\
\hline Total & 1758 & 11 & & & & \\
\hline
\end{tabular}

The results of the dispersion analysis also refute the hypothesis of the study. Thus, it can be confidently asserted that a change in the quality of assessment of the competencies is significant, and not accidental.

Among the essential structural components of any pedagogical system and learning process is content. The possibility of implementation of the main principles of didactics creates the basis for material selection. However, the development and application of methodological criteria are necessary for the curriculum content of a particular ac- 
ademic section. Thus, when choosing the content of professionally oriented courses, the following criteria are considered:

- Tasks should contribute to the formation of a comprehensively developed personality.

- Content should have high scientific and practical significance.

- - content complexity should correspond to the real educational capabilities of students

- Content amount should correspond to the available time for studying.

The innovative educational process is based on a modular competency-based approach and performed in several stages. The first is the stage of modeling the educational process, at which levels of study of the academic discipline are established. The second stage involves the design of educational content based on the educational standard of the country and a competency passport. For this aim, the principal functions that make up the chosen profession and determine the challenges of professional and applied training, the resolution of which requires mastering the appropriate discipline, are described. The third stage is the design of modular programs and training modules. In the fourth stage, the implementation of the model and its further improvement is conducted. In the last fifth stage, the analysis, evaluation, and development of teacher's recommendations to improve the educational model are performed. As an example, the study presents the application of a modular competency-based approach to the organization of professional training within the training program 21.03.01 "Oil and Gas Business" (Table 5).

The objective of studying the modules of professional training by specialists in the oil and gas industry lies in the development of modern statistical methods and models to improve the organization of laboratory and field experiments. It is also aimed at ensuring the reliability of the information base when developing mathematical models of technological processes for drilling wells. Besides the main modules related to the application of probabilistic and statistical analysis, as well as the methods of the theory of experimental design, such modules as "Methods of the Theory of Pattern Recognition" and "Mathematical Modeling of Technological Processes for the Transportation of Oil and Gas Products" are also added. 
Table 5. The main modules of professional training

\begin{tabular}{|c|c|}
\hline Module name & Content \\
\hline $\begin{array}{l}\text { 1. The Use of Probabilistic and } \\
\text { Statistical Analysis in the } \\
\text { Field of Mathematical Model- } \\
\text { ing in the Oil and Gas Industry }\end{array}$ & $\begin{array}{l}\text { Probability distribution laws; distribution of the size of rock or particles } \\
\text { during crushing; the Poisson distribution; determination of the failure time } \\
\text { of the well lining due to the influx of waters of primary cementing taking } \\
\text { into account the service life of the wells. Parametric and nonparametric } \\
\text { tests; testing the hypothesis of the exponential law of the distribution of the } \\
\text { appearance time of drilling fluid with a density higher or lower than the } \\
\text { nominal value at the wellhead; verification of the hypothesis of a limited } \\
\text { data belonging to the normal distribution law; Shapiro-Wilk test, testing the } \\
\text { measurement results of the drilling fluid loss and their belonging to the } \\
\text { generalized normal distribution. Dispersion, correlation, and regression } \\
\text { analysis; control of the drilling fluid loss according to the results of meas- } \\
\text { urements and their belonging to the generalized normal distribution. Multi- } \\
\text { variate analysis of variance of changes in the properties of Portland cement } \\
\text { mortar when mixed with different volumes of oil (water loss, static shear } \\
\text { stress, the start and end time of setting, a tensile strength in bending after } 2 \\
\text { days). The Kruskal-Wallis test by ranks of vertical borehole curvature } \\
\text { when drilling depth from } 2400 \text { to } 2850 \text { m with three different layouts (A, } \\
\text { B, C) of the bottom of the drill string for samples from five wells; correla- } \\
\text { tion and regression analysis in constructing the regression equation based } \\
\text { on the results of experiments aimed to study the change in the strength of } \\
\text { two-day cement stone. }\end{array}$ \\
\hline $\begin{array}{l}\text { 2. Methods of the Experiment } \\
\text { Planning Theory } \\
\end{array}$ & $\begin{array}{l}\text { Research related to the study of the mechanism of various phenomena; } \\
\text { experimental search for optimal conditions; assessment of the significance } \\
\text { of the effect on of the drilling fluid loss and composition components (clay, } \\
\text { weighting agent, lime, calcium chloride, oxyl, carboxymethyl cellulose, oil } \\
\text { and graphite in cold conditions) within } 30 \text { minutes; designing an experi- } \\
\text { ment according to the plan of Plackett-Berman; evaluation of the effect on } \\
\text { the depression of an inflow stimulation, drilling fluid types, fluid loss re- } \\
\text { ducer, viscosity reducer, and also the method of perforation; design of a } \\
\text { cement slurry formulation for cold conditions (bottom-hole temperature } 25 \\
\ldots 30^{\circ} \mathrm{C} \text { ), which provides a minimum deviation from the time of setting and } \\
\text { consists of a fluid loss reducer and setting time accelerator; optimization of } \\
\text { drilling mode parameters i.e. selection of axial load on the bit and rotational } \\
\text { speed; cementing of wells with a bottom-hole temperature of } 100^{\circ} \mathrm{C} \text {; design } \\
\text { of sedimentation-resistant cement slurry formulation; determination of the } \\
\text { appropriate change in the conditions noted during drilling to increase pene- } \\
\text { tration by the bit. }\end{array}$ \\
\hline $\begin{array}{l}\text { 3. Methods of the Pattern } \\
\text { Recognition Theory }\end{array}$ & $\begin{array}{l}\text { Assessment of probable situations to predict the possible nature of the } \\
\text { process and make decisions on the choice of control actions for efficient } \\
\text { work; indicators of the properties of working agents (drilling mud, grouting } \\
\text { mixture, etc.), operating characteristics of the equipment (mud pump rate, } \\
\text { rotor torque, pressure in the elements of the circulation system, etc.), in- } \\
\text { formation on external influences (reservoir pressure and temperature, rock } \\
\text { and fluid properties, bedding angles, etc.), and the nomenclature of materi- } \\
\text { als and equipment used. }\end{array}$ \\
\hline $\begin{array}{l}\text { 4. Mathematical Modeling of } \\
\text { Technological Processes for } \\
\text { the Transportation of Oil and } \\
\text { Gas Products }\end{array}$ & $\begin{array}{l}\text { Thermal calculation of the pipeline; changes in the volume of the pipeline } \\
\text { depending on temperature and pressure; dependence of the hydraulic re- } \\
\text { sistance coefficient on the diameter of the pipeline and the pumping flow; } \\
\text { increase in the speed of oil flow in the pipeline when using an anti- } \\
\text { turbulent additive; gravity flows in pipelines; design calculation for oil } \\
\text { pipelines and compressor stations; design calculation for the centrifugal } \\
\text { supercharger; design calculation for a water hammer in the pipeline section; } \\
\text { calculation for oil transmix. }\end{array}$ \\
\hline
\end{tabular}


The introduction of the module "Methods of the Theory of Pattern Recognition" is necessary since in the oil and gas industry there is the need to predict the possible nature of the process and decide on the choice of controlling actions for efficient work. The main tasks of the theory of pattern recognition can be considered as follows:

- Object recognition or discrimination (assignment of an object or situation to a particular category).

- Object classification and clustering (objects' division into groups with common properties).

The need to introduce the "Mathematical Modeling of Technological Processes for the Transportation of Oil and Gas Products" is associated with the fact that in the oil and gas industry, when implementing complex technological processes, many tasks may arise (Table 6).

Table 6. Mathematical Modeling of Technological Processes for the Transportation of Oil and Gas Products

\begin{tabular}{|c|c|c|}
\hline No. & Module sections & Content \\
\hline 1. & $\begin{array}{l}\text { Thermal calculation of } \\
\text { the pipeline }\end{array}$ & $\begin{array}{l}\text { Heating is used to reduce hydraulic losses during the pumping of highly } \\
\text { viscous oils and petroleum products. When moving through the pipeline, } \\
\text { the oil product cools down. } \\
\text { The section discusses the distribution of oil product temperature along } \\
\text { the pipeline, which allows more accurate determination of hydraulic } \\
\text { losses. }\end{array}$ \\
\hline 2. & $\begin{array}{l}\text { Changes in the volume of } \\
\text { the pipeline depending on } \\
\text { temperature and pressure }\end{array}$ & $\begin{array}{l}\text { Most bodies expand when heated. Thus, if they are exposed to internal } \\
\text { pressure, their geometric dimensions can increase significantly. } \\
\text { The section examines the effect of changes in temperature and internal } \\
\text { pressure on changes in the pipeline volume. }\end{array}$ \\
\hline 3. & $\begin{array}{l}\text { Dependence of the hy- } \\
\text { draulic resistance coeffi- } \\
\text { cient on the diameter of } \\
\text { the pipeline and the } \\
\text { pumping flow }\end{array}$ & $\begin{array}{l}\text { During transportation, between the pipeline wall and the oil occurs fric- } \\
\text { tion, which is considered as a hydraulic resistance coefficient. This coef- } \\
\text { ficient is crucial since it is possible to determine the pressure losses along } \\
\text { the length of the pipeline by its value and, accordingly, choose pumping } \\
\text { equipment that will overcome these losses. The hydraulic resistance } \\
\text { coefficient depends on the flow rate and the geometric characteristics of } \\
\text { the pipeline. } \\
\text { The section presents the determination of the dependence of the hydrau- } \\
\text { lic resistance coefficient on the diameter of the pipeline and pumping } \\
\text { flow. }\end{array}$ \\
\hline 4. & $\begin{array}{l}\text { Increase in the speed of } \\
\text { oil flow in the pipeline } \\
\text { when using an anti- } \\
\text { turbulent additive }\end{array}$ & $\begin{array}{l}\text { Friction losses remain the main reason for energy expenses when pump- } \\
\text { ing liquids and gases through pipelines. Friction losses are caused by the } \\
\text { internal friction between the layers of moving fluid and the inner surface } \\
\text { of the pipeline. Both in the laminar and the turbulent flow, the mechani- } \\
\text { cal energy of motion is dissipated, and the fluid movement becomes } \\
\text { chaotic. One of the ways to reduce energy loss is the introduction of } \\
\text { special high molecular weight additives in the turbulent flows. The } \\
\text { mechanism of action of all anti-turbulent additives is based on the sup- } \\
\text { pression of the near-wall turbulence in pipes due to the interaction of } \\
\text { long additive molecules with turbulent vortexes. Due to the suppression } \\
\text { of near-wall turbulence, the hydraulic resistance exerted by the pipe flow } \\
\text { decreases. Hence, either an increase in pumping capacity or a pressure } \\
\text { reduction at the pumping stations is achieved. The effect of hydraulic } \\
\text { resistance reduction, as well as electricity consumption, can vary from } 20\end{array}$ \\
\hline
\end{tabular}




\begin{tabular}{|c|c|c|}
\hline & & $\begin{array}{l}\text { to } 60 \% \text {. Among the well-known foreign additives to petroleum products, } \\
\text { the American additive CDR of the company Dupon-Conoco and the } \\
\text { additive NECCAD-547 of the Finnish company Neste can be distin- } \\
\text { guished. These additives are developed on a carbon basis. The first addi- } \\
\text { tive is equally suitable for pumping both gasoline and diesel fuels, while } \\
\text { the second one is recommended for pumps with diesel fuel. The use of } \\
\text { anti-turbulent additives has a limitation - additives are destroyed after the } \\
\text { prolonged action in a turbulent flow, especially after passing through the } \\
\text { compressor stations. Therefore, after each compressor station, it is neces- } \\
\text { sary to add new portions of additives into the flow. } \\
\text { The section discusses the determination of the increase in the speed of oil } \\
\text { products in the pipeline when using an anti-turbulent additive. }\end{array}$ \\
\hline 5. & Gravity flows in pipelines & $\begin{array}{l}\text { When transporting oil products in the pipeline, there can be sections, } \\
\text { where the petroleum product flows at partial (gravity) flow. Gravity flow } \\
\text { is a section of a pipe, where air pockets occur, and oil moves by a cross- } \\
\text { section under the influence of gravity. The pressure in such air pockets is } \\
\text { almost constant and equal to the elastic pressure of the saturated vapor of } \\
\text { the oil product. Accordingly, the flow in the gravity section is also called } \\
\text { free-flow. However, the difference in pressure between the beginning } \\
\text { and end of the gravity flow exists. It is equal to the difference in the } \\
\text { heights of the flow sections. Gravity flows with air pockets can exist only } \\
\text { in the descending pipeline sections. Among the main parameters of the } \\
\text { gravity flow is the degree of its filling with an oil product on the particu- } \\
\text { lar section } \sigma \text {. By the value of } \sigma \text {, it is possible to determine the flow rate } \\
\text { of the petroleum product and clarify the coefficient of hydraulic re- } \\
\text { sistance. } \\
\text { The section discusses gravity flows in pipelines. }\end{array}$ \\
\hline 6. & $\begin{array}{l}\text { Design calculation for oil } \\
\text { pipelines and compressor } \\
\text { stations }\end{array}$ & $\begin{array}{l}\text { On a line pipe, the oil products flow from a section with high pressure to } \\
\text { the lower one. The constant pressure decrease can be explained with the } \\
\text { expenditure of energy to overcome the friction forces. Consequently, for } \\
\text { the movement of the petroleum product in the pipeline, pumps are need- } \\
\text { ed. Each of them has its head and rate specification } \Delta H=F(Q) \text {. Besides, } \\
\text { they can be connected in parallel or series-parallel to each other to ensure } \\
\text { better productivity of oil compressor stations. } \\
\text { The section reviews the design calculation for oil pipelines and compres- } \\
\text { sor stations, examines the influence of the parameters at the outlet of the } \\
\text { pumping station on the oil flow rate and pressure at the end of the pipe- } \\
\text { line section. }\end{array}$ \\
\hline 7. & $\begin{array}{l}\text { Design calculation for the } \\
\text { centrifugal supercharger }\end{array}$ & $\begin{array}{l}\text { Gas is transported through pipelines by compressor stations equipped } \\
\text { with pumping units. Superchargers, together with gas turbine units } \\
\text { (GTU), make a gas-pumping unit (GPU). The task of the GTU is to ro- } \\
\text { tate the shaft of the centrifugal supercharger. The centrifugal super- } \\
\text { charger is aimed at forcing the gas from the low-pressure line (suction } \\
\text { line) to the high-pressure line (discharge line). When changing the } \\
\text { productivity of the pipeline, or increasing its length, in most cases, a new } \\
\text { compression ratio and the number of revolutions of the GTU is calculat- } \\
\text { ed. } \\
\text { The section presents the design calculation of the centrifugal super- } \\
\text { charger. }\end{array}$ \\
\hline 8. & $\begin{array}{l}\text { Design calculation for a } \\
\text { water hammer in the } \\
\text { pipeline section }\end{array}$ & $\begin{array}{l}\text { Water hammer is the result of a pressure surge or high-pressure shock- } \\
\text { wave that propagates through a piping system when a fluid in motion is } \\
\text { forced to change direction or stop abruptly. The possibility of water } \\
\text { hammer should be taken into account when designing and operating oil } \\
\text { product pipelines, since the shock pressure can far exceed the permissible } \\
\text { norms, leading to the pipe rupture. The need to reckon with the destruc- } \\
\text { tive force of water hammer in liquid pipelines is since the valves, that } \\
\text { immediately stop the cross-sectional area, are never installed on such } \\
\text { pipes. Liquid pipelines use valves that provide a slow cross-section clo- }\end{array}$ \\
\hline
\end{tabular}




\begin{tabular}{|l|l|l|}
\hline | & & $\begin{array}{l}\text { sure. As a result of the water hammer, air pockets may occur. They sig- } \\
\text { nificantly reduce the flow and cause increased pipeline vibration. To } \\
\text { protect the pipe from the consequences of a water hammer, oil pumping } \\
\text { stations use specialized devices. } \\
\text { The section reviews the design calculation of a water hammer in the } \\
\text { pipeline section. }\end{array}$ \\
\hline 9. & $\begin{array}{l}\text { At present, in Russia and abroad, light petroleum products, gasoline, } \\
\text { kerosene, diesel fuels, and the like are pumped by the sequential pump- } \\
\text { ing. Within this method, multi-grade petroleum products, combined into } \\
\text { separate batches of several thousand tons each, are pumped one after the } \\
\text { other, and transported to the consumer. The mixing of oil products poses } \\
\text { a relatively small risk to lower oil product quality since the petroleum } \\
\text { products belonging to the same type are more compatible with each other } \\
\text { than oil products with different compositions. The mixture of such petro- } \\
\text { leum products as gasoline and diesel fuels, or gasoline and kerosene, } \\
\text { poses a serious threat to their quality. Modes of transportation of petrole- } \\
\text { um products should be selected from the conditions of the minimum } \\
\text { volume of the mixture area and the capabilities of pumping equipment. } \\
\text { The section discusses the calculation for oil transmix. }\end{array}$ \\
\hline
\end{tabular}

The scientific novelty of the study is in the process of increasing the level of professional competence of bachelors in the field of mathematical modeling in the oil and gas industry. Based on a professionally oriented integrative approach, an innovative system of differentiation of mathematical profiles is developed. Here, the generalized mathematical methods for analyzing the production process in the petroleum industry serve as the key knowledge sources. The problem of designing the content of professionally directed modules in the field of mathematical modeling in the oil and gas business is solved at the scientific, theoretical, and practical levels. Furthermore, within the framework of the research, the differentiated indicators which determine the formation of professional mathematical competence among university students are examined.

The theoretical significance of the study lies in the development of technical support of the innovative educational process. It is worth noticing that this support is based on a modular competency approach. Additionally, the mathematical competency which characterizes the degree of students mastering the knowledge and skills is determined as a core component of the university students' professional competency. The present study proves the effectiveness of the profile differentiation of students' mathematical training.

The practical significance of the study is that the content of the main modules of professional training in the field of modeling in the oil and gas industry it developed. The results of the study can be used in the process of mathematical education of students in educational institutions with disciplines of the corresponding profile. During the implementation of the current teaching technology, training programs, and study guides for "Operation and Maintenance of Oil Production Facilities" and "Operation and Maintenance Services for Oil and Gas Production Facilities" educational specializations are developed. The study guides can be added to the lecture course since they promote the consolidation of the theoretical skills by solving professional tasks. 


\section{Discussion}

In the study, on the basis of a modular competency-based approach, the profile differentiation of the mathematical preparation of students in the training program 21.03.01 "Oil and Gas Business" is improved. Many similar or close methods of differential training of students with an emphasis on mathematical statistics exist [35]. Among the most effective is STEM. This technique involves a more precise definition of the practical goals of training and achieving competencies in solving professional problems $[8,19]$. Mathematical modeling is easily integrated into the learning process without interruption of the practice. Such methods can solve many educational difficulties. In Russia, the application of this method may be somewhat complicated due to the lack of technical means for modeling real situations and challenges in the oil and gas industry. However, this problem can be resolved by applying digital modeling $[1,9,36]$.

The identification of mathematically gifted students [9,35,37] plays a key role in training. Early talent recognition and development enable better specialist training and enhances a person's potential. Methods for the development of talent and creativity in solving mathematical problems make it possible to create a unique competence for solving unpredictable problems in real life, especially, in extreme situations or when certain technological violations occur.

The use of mathematical competencies for making managerial decisions is among the crucial issues for the oil and gas industry. The matter of this competency formation is considered one of the most important by many researchers. The application of mathematical analysis and probabilistic methods in predicting system behavior, choosing managerial decisions, and managing stocks of companies is also examined very carefully $[6,23]$.

The conducted examinations cannot pretend to be an exhaustive scientific description of all aspects of the profile differentiation of the mathematical preparation due to the increased requirements for the implementation of professional tasks. Among the issues that require further investigation, the following can be stated:

- Development of an advanced system of mathematical profile differentiation;

- Improvement of modern methods for the approbation of the experimental results.

\section{Conclusion}

An experimental study of the proposed modular methodology for increasing mathematical competence shows relevant positive differences in the levels of formed competencies among students. Based on an analysis of mathematical training, a modular competency-based approach to the organization of professional education for specialists within the training program 21.03.01 "Oil and Gas Business" is implemented. The content of training modules is aimed at developing of modern statistical methods and models by students to increase the efficiency of organizing laboratory and field experiments. The training modules' content should also guarantee the reliability of the in- 
formation concerning the development of mathematical models of well drilling. Besides, mathematical training modules should conduct an assessment of various situations that may arise to predict the possible nature of the process and make decisions on the selection of actions toward efficient work. They are to control petroleum products' transportation, design calculation oil transmix, the capabilities of oil pumping equipment, water hammer, the dependence of the hydraulic resistance coefficient on the diameter of the pipeline, and the pumping flow.

According to the results of the research, on the basis of a modular competency approach, a methodology that allows implementing profiling of the mathematical education of university students is developed. As a result of a theoretical and experimental analysis of existing standards, curricula, programs, and textbooks, the content of professionally directed modules are determined. Thus, various teaching materials can be created to ensure the professional orientation of the students' mathematical training (guidelines, textbooks, lectures, collections of practical tasks and exercises, technical teaching aids).

\section{$7 \quad$ References}

[1] Ershaghi, and D. L. Paul, “The Changing Shape of Petroleum Engineering Education,” In SPE Annual Technical Conference and Exhibition. Society of Petroleum Engineers, 2017. https://doi.org/10.2118/187115-MS

[2] Gonzalez, J. L. V., Aviles, J. B., Muñoz, A. R., \& Palomares, R. A., “An industrial automation course: common infrastructure for physical, virtual and remote laboratories for PLC programming," International Journal of Online and Biomedical Engineering (iJOE), vol. 14, no. 08, pp. 4-19, 2018. https://doi.org/10.3991/ijoe.v14i08.8758

[3] A. Kisabekova, "Teaching students of physical specialties to solve interdisciplinary problems by the method of mathematical modeling," Omsk scientific bulletin, vol. 4, no. 79, pp. 176-178, 2009.

[4] S. Chowdhury, Optimization and Business Improvement Studies in Upstream Oil and Gas Industry. John Wiley \& Sons, 2016. https://doi.org/10.1002/9781119246596

[5] N. Yu. Gorbunova, "Applying professionally oriented problems of mathematical modeling in teaching students of engineering departments," Modern studies of social issues, vol. 8, no. 4, pp. 86-100, 2017.

[6] B. Badiru, and S. O. Osisanya, Project management for the oil and gas industry: a world system approach. CRC Press, 2016. https://doi.org/10.1201/b13755

[7] J. D. Jansen, (2017). Nodal Analysis of Oil and Gas Production Systems. Society of Petroleum Engineers.

[8] G. C. Gonzalez, C. J. Doss, J. H. Kaufman, and R. Bozick, "Supporting Middle-Skills STEM Workforce Development: Analysis of Workplace Skills in Demand and Education Institutions' Curricular Offerings in the Oil and Gas Sector," Research Report. RR-2899NSF, RAND Corporation, 2019. https://doi.org/10.7249/RR2899

[9] F. M. Singer, Mathematical Creativity and Mathematical Giftedness: Enhancing Creative Capacities in Mathematically Promising Students. Springer, 2018. https://doi.org/10.1007/ 978-3-319-73156-8_1

[10] R. N. Zaripov, and M. N. Goryntseva, "Evaluation of human potential as the basis of the risk reduction mechanism for creating unique high-tech products: problem statement and solution," Economics and Entrepreneurship, vol. 9, pp. 1049-1052, 2018. 
[11] V. V. Utemov, R. M. Khusainova, M. G. Sergeeva, and Shestak, V. A. "Full packaged learning solutions for studying mathematics at school," Eurasia Journal of Mathematics, Science and Technology Education, vol. 14, no. 12, em1619.

[12] R. N. Zaripov, "Features of Identification and Analysis of Risks of R\&D of the Hi-tech Industrial Enterprise," In 2018 Eleventh International Conference "Management of largescale system development" (MLSD), IEEE, 2018, pp. 1-4. https://doi.org/10.1109/ MLSD.2018.8551833

[13] V. M. Monakhov, A. P. Silchenko, and S. A. Tikhomirov, "Genesis and Function of Professional Pedagogical Activity in Terms of IEE," Yaroslavl Pedagogical Bulletin, vol. 6, 2017.

[14] V. M. Monakhov, and F. V. Monakhov, "Education and communicational technology," Social Communication and the Evolution of Society, pp. 327-334, 2018.

[15] M. B. Alieva, and E. M. Yesenova, "The possibility of using "case-study" technology in professionally oriented training of students," Innovation Science, vol. 1, pp. 76-78, 2016

[16] Kh. A. Alizhanova, and R. T. Gadzhimuradova, "The methodological framework, strategy, objectives and goals of specialized education," Bulletin of KSU named after N. Nekrasov, vol. 22, pp. 14-17, 2016.

[17] L. K. Ilyashenko, "Informative characteristics and methods of the formation mathematical competence of future engineer in the oil and gas business," Revista Espacios, vol. 39, no. $05,2018$.

[18] C. G. Isaeva, and Sh. A. Magomedov, "Profilisation of the educational process as a comprehensive preparation for professional activity," Bulletin of Chelyabinsk State University, vol. 2, pp. 63-71, 2015.

[19] K. F. Gabdrkhmanova, G. R. Izmailova, and L. Z. Samigullina, "Task Approach in the Bachelors' Professional Competence Formation," In International Scientific Conference "Far East Con" (ISCFEC 2020), Atlantis Press, 2020, pp. 2727-2732. https://doi.org/10.2 991/aebmr.k.200312.386

[20] V. I. Zagvyazinsky, "About a systemic approach to reforming education," Pedagogy, vol. 1, pp. 12-18, 2016

[21] L. D. Kudryavtsev, Modern mathematics and its study. Nauka, 1980.

[22] Yu. M. Kaliagin, and O. L. Alekseenko, "Integration of school education," Elementary School, vol. 9, pp. 28-29, 1990.

[23] C. J. Pamela, G. I. Umoh, and G. Worlu, "Human resource planning and organizational performance in oil and gas firms in Port Harcourt," Human Resource Planning, vol. 3, no. 9, 2017.

[24] K. Dishlieva, "From the Secondary School to the Technical University, Or One Difficult Year for the First-Year Students," Bulgarian Journal of Science and Education Policy, vol. 4, no. 2, pp. 248-274, 2010.

[25] H. Ozturk, "Evidence-Based Policies on Mathematics Education in Europe," Science \& Philosophy, vol. 1, no. 2, pp. 161-168, 2014.

[26] E. S. Hoji, W. B. Vianna, and T. A. Félix, "Computer-aided Teaching of Math in Electromechanics Vocational Course," International Journal of Engineering Pedagogy, vol. 3, no. S2, pp. 39-45, 2013. https://doi.org/10.3991/ijep.v3iS2.2445

[27] R. D. Taylan, and J. P. da Ponte, "Investigating pedagogical content knowledge-in-action," REDIMAT - Journal of Research in Mathematics Education, vol. 5, no. 3, pp. 212-234, 2016. https://doi.org/10.17583/redimat.2016.2227

[28] T. Nicolini, C. S. Santos, H. C. Hoeschl, and I. Theiss, "Using Competence Modeling to create Knowledge Engineering Team," In IFIP WCC TC12 2006: Professional Practice in Artificial Intelligence, 2006, pp. 151-159. https://doi.org/10.1007/978-0-387-34749-3 16

[29] M. Mulder, "Conceptions of Professional Competence," in International Handbook of Research in Professional and Practice-based Learning, 2014, pp-107-137. https://doi.org/ $\underline{10.1007 / 978-94-017-8902-8 \_5}$ 
[30] F. Depaepe, L. Verschaffel, and J. Star, "Expertise in developing students' expertise in mathematics: Bridging teachers' professional knowledge and instructional quality," $Z D M$, vol. 52, 2020. https://doi.org/10.1007/s11858-020-01148-8

[31] R. Gutiérrez, "Embracing Nepantla: Rethinking "Knowledge" and its Use in Mathematics Teaching," REDIMAT - Journal of Research in Mathematics Education, vol. 1, no. 1, pp. 29-56, 2012.

[32] K. Choi, "A study on literature review of mathematical modeling in mathematical competencies perspective", Journal of the Korean school mathematics society, vol. 20, no. 2, pp. 187-210, 2017.

[33] K. H. Hauge and R. Barwell, "Post-normal science and mathematics education in uncertain times: Educating future citizens for extended peer communities," Futures, vol. 91, pp. 2534, 2017. https://doi.org/10.1016/j.futures.2016.11.013

[34] Y. Ramdani, and O. R. Dianita, O. "Increasing Indicators of Mathematics Competency in Integral Concept Through Debate Scientific Strategy", International Journal of Innovation and Research Education Science (IJIRES), vol. 5, no. 1, 2018.

[35] M. Akimzhanova, G. Ilyassova, A. Nukusheva, and D. Rustembekova, "Extending Legislation of the Republic of Kazakhstan by Anchoring International Child Rights," Journal of Legal, Ethical and Regulatory Issues, vol. 21, no. 3, 2018.

[36] B. Nwachukwu, "Corrosion Measurement in Oil and Gas Pipeline: A Mathematical Model Approach," In SPE Nigeria Annual International Conference and Exhibition, Society of Petroleum Engineers, 2018. https://doi.org/10.2118/193409-MS

[37] S. Tejeda, and K. Gallardo, "Performance assessment on high school advanced algebra," International Electronic Journal of Mathematics Education, vol. 12, no. 3, pp. 777-798, 2017.

\section{Authors}

Anatoly Kozlov is a Doctor of Pedagogical Sciences. He is a Head of the Department of Transport and Technologies of Oil and Gas Complex at Branch of Tyumen Industrial University in Noyabrsk, Noyabrsk, Russia. His research interests include modeling technical systems and processes.

Olga Tamer is a Doctor of Pedagogical Sciences. She is a Head of the Department of Applied Mathematics and Natural Sciences at Branch of Tyumen Industrial University in Noyabrsk, Noyabrsk, Russia. Her research interest is role of mathematics and computer science for professional competency of educators.

Svetlana Lapteva is a Candidate of Pedagogical Sciences. She Assistant Professor at the Department of Transport and Technologies of Oil and Gas Complex at Branch of Tyumen Industrial University in Noyabrsk, Russia. Her research interests are informatics, organization and planning of automated production, computer telecommunication networks.

Article submitted 2020-04-12. Resubmitted 2020-05-13. Final acceptance 2020-05-15. Final version published as submitted by the authors 